\title{
TITLE:
}

\section{Cell surface modification with polymers for biomedical studies}

$\operatorname{AUTHOR}(S)$ :

Teramura, Yuji; Iwata, Hiroo

\section{CITATION:}

Teramura, Yuji ... [et al]. Cell surface modification with polymers for biomedical studies. Soft Matter 2010, 6(6): 1081-1091

\section{ISSUE DATE:}

2010

URL:

http://hdl.handle.net/2433/156399

\section{RIGHT:}

(C) Royal Society of Chemistry 2010.; この論文は出版社版でありません 。引用の際には出版社版をご確認ご利用ください。; This is not the published version. Please cite only the published version. 
Review article for Soft Matter

\section{Cell Surface Modification with Polymers}

for

\section{Biomedical Studies}

Yuji Teramura $^{1}$ and Hiroo Iwata ${ }^{2} *$

${ }^{1}$ Radioisotope Research Center, Kyoto University, Yoshida-Konoe-cho, Sakyo-ku,

Kyoto, 606-8501, Japan, ${ }^{2}$ Department of Reparative Materials, Institute for Frontier

Medical Sciences, Kyoto University, 53 Kawara-cho, Shogoin, Sakyo-ku, Kyoto, 606-

8507, Japan.

* Address correspondence and reprint requests to Hiroo Iwata, Ph.D.

E-mail: iwata@frontier.kyoto-u.ac.jp, PHONE/FAX: +81-75-751-4119 


\section{Summary}

Surface modification of living cells with natural or synthetic polymers is a powerful and useful tool in biomedical studies. Various functional groups and bioactive substances can be immobilized to the cell surface through covalent conjugation, electrostatic interaction, or hydrophobic interaction. In this review, we provide an overview of the methods and polymers employed in cell surface modification, including: (1) covalent conjugation utilizing amino groups of cell surface proteins, (2) electrostatic interaction between cationic polymers and a negatively charged cell surface, and (3) hydrophobic interaction of amphiphilic polymers with the lipid bilayer membrane. We also discuss their applications in studies on cell transplantation, cell-cell interaction analysis, cell arrangement, and lineage determination of stem cells. 


\section{Introduction}

Surface modification of living cells with natural and synthetic polymers allows for new opportunities in biomedical engineering and science. A variety of functional groups and bioactive substances have been introduced onto the cell surface. The three methods generally employed in cell surface modification are covalent conjugation, electrostatic interaction, and hydrophobic interaction.

In this review, we provide an overview of the methods and polymers employed in cell surface modification in conjunction with their applications in biomedical engineering and science; applications discussed include: (1) adding biological functions, such as blood compatibility, to the cell surface, (2) controlling graft rejection in cell transplantation by masking surface antigens of cells with natural or synthetic polymers, and (3) aligning different kinds of cells through interactions between complementary units, such as oligoT and oligoA, introduced on different cell surfaces. Cell surface modification, still an emergent research area, can be used to study cell-cell interaction and to control stem cell lineages in regenerative medicine. It is anticipated cell surface modification technology will soon be applied to the treatment of patients in the areas of regenerative medicine, tissue engineering, stem cell research, and embryology. 


\section{Methods for cell surface modification}

Surface modification of cells has been generally achieved through three methods: (1) covalent conjugation to amino groups of cell surface proteins, (2) electrostatic interaction between cationic polymers and a negatively charged surface, and (3) incorporation of amphiphilic polymers into the lipid bilayer membrane of cells by hydrophobic interaction. The methods are summarized in Fig. 1. Attempts have been made with various kinds of synthetic and natural polymers for surface modification of cells and biomaterials. ${ }^{1,2}$ Poly(ethylene glycol) (PEG) is currently considered a suitable, biocompatible material for surface modification; PEG is a hydrated, flexible polymer chain (Fig. 1a), which works as a steric barrier on the cell surface.

\subsection{Covalent bond method}

For covalent conjugation of polymers, surface modification of living cells has been achieved through chemical or enzymatic treatment or by metabolic introduction. ${ }^{3-11}$ As shown in Fig. 1b, the $N$-hydroxyl-succinimidyl ester (NHS) group and cyanuric chloride are generally used to chemically form covalent amide bonds to membrane proteins. ${ }^{7-11}$ These groups mainly react with amino groups of protein; however, there is a potential 
for denaturation membrane proteins or be cytotoxic due to the chemical modification of membrane and cytoplasmic proteins. ${ }^{3,4}$

Enzymatic treatment and metabolic introduction have been applied to cell lines to add various molecules such as biotin, azide, and ketone groups to living cell surfaces. ${ }^{3-6}$ The introduction of these molecules enables cells to gain new biological functions.

However, these procedures are difficult to apply to primary cells in culture or cells to be transplanted, such as islets. In addition, the technologies are limited to the introduction of specified functional small molecules to specified cells and might perturb cell physiology. ${ }^{5,6}$ Finally, although covalent immobilization was expected to be stable for chemical degradation and present for a long time because of covalent bonding to membrane proteins, polymers disappeared from the cell surface with time. ${ }^{7,9,14}$

\subsection{Hydrophobic interaction-based cell surface modification using amphiphilic}

\section{polymers}

Amphiphilic polymers such as PEG-conjugated phospholipids (PEG-lipid) and poly(vinyl alcohol) bearing alkyl side chains (PVA-alkyl), have been used for cell surface modification as a noncovalent cell surface modification technique (Fig. 1c). ${ }^{5,6,12-}$

${ }^{18}$ In this method, amphiphilc polymers are simultaneously introduced into the lipid 
bilayer membranes by hydrophobic interactions, without cytotoxicity. This surface modification does not cause protein denaturation or affect cell function. PEG-lipid has been widely used for the surface modification of liposomes. ${ }^{19,20}$ Surface modification with PEG-lipid prolongs circulation time in vivo and improves biocompatibility. PEGlipid is an amphiphilic molecule which is composed of a hydrophilic PEG chain and hydrophobic phospholipid. The PEG chain can be anchored to the cell surface because the hydrophobic part of PEG-lipid is spontaneously incorporated into the lipid bilayer membrane when PEG-lipid is mixed with cells (Fig. 2a). It is possible to form the PEG layer at a several nanometer level on the cell surface, depending on the molecular weight of PEG. This spontaneous incorporation can be monitored by a surface plasmon resonance (SPR) instrument when PEG-lipid solution is applied onto the supported lipid membrane (Fig. 2b). Small unilamellar vesicles are applied to methyl-terminated selfassemble monolayer (SAM) surfaces to form the supported lipid membrane. Then, PEG-lipid solution is applied and the incorporation into the membrane is monitored. The spontaneous incorporation of PEG-lipid can be observed and it is greatly affected by the hydrophobicity of the phospholipid.

To demonstrate the surface modification of cells with PEG-lipid, CCRF-CEM (Human cell line derived from $\mathrm{T}$ cell leukemia) floating cells were used. FITC was conjugated 
to the end of the PEG chain of PEG-lipid for fluorescence labeling. Cells were incubated in FITC-PEG-lipid solution for $30 \mathrm{~min}$ at room temperature. After washing with PBS, treated cells were observed with a confocal laser scanning microscope (Fig. 2c). The fluorescence of FITC was observed at the periphery of all cells, indicating PEG-lipids were anchoring to the lipid bilayer membrane of cell surfaces by hydrophobic interaction. PEG-lipids were gradually disappeared from the cell surface without uptake into the inside of cells. They were dissociated from cell surface into medium as seen in Fig. 2(b). Cell viability was assessed by the trypan blue exclusion method. There was no cytotoxicity in cells treated with FITC-PEG-lipid as PEG is biocompatible and phospholipids are components of cell membranes. This method can also be applied to the surface modification of adherent HEK293 cells with PEG-lipid. Another type of amphiphilic PVA derivative carrying long alkyl side chains can be also used for surface modification, allowing interactions with the cell membrane at multiple points. It was observed that PVA-alkyls gathered at an area on the membrane, similar to the capping phenomena observed on lymphocytes treated with polyvalent antibodies. $^{14}$

\section{$\underline{\text { 2.3. Electrostatic interaction }}$}


Several groups have explored the possibility of constructing thin polymer membranes on the surface of cells or islets using layer-by-layer of anionic and cationic polymers such as poly(allylamine hydrochloride) (PAH), poly(styrene) sulfate (PSS), poly-Llysine (PLL), and poly(ethyleneimine) (PEI), as shown in Fig. 1d and e. ${ }^{21-25}$ Cationic polymers interact with negatively charged cell surfaces and anionic polymers are treated to form layer-by-layer membranes as the procedure is repeated. However, most polycations were found to be extremely cytotoxic and severely damaged treated cells. When cells were mixed with PEI solution, PEI exerted an immediate toxic effect on cells ${ }^{14}$ by strongly interacting with the cell, destroying the cell membrane, and invading the cells by simple incubation. No clear change in PEI was seen on dead cells over 2 days. PEI which interacted with cell was not degraded and not excluded from the cell because PEI immediately destroyed the cell membrane after interaction with cell surface. In contrast, no bright ring or spots were observed on/in cells exposed to the FITClabeled anionic polymers. The polyanions did not adsorb on the cell surface or exert toxic effects on the cells.

\subsection{Layer-by-layer method}


A layer-by-layer method is a simple method to form a thin polymer membrane on the cell surface. ${ }^{26}$ The surface property can be controlled by the outermost layer of polymer. The thickness of the membrane is also controllable by the number of applications of polymer solution. The technique is used for the surface modification of living cells. In most cases, the formation of layer-by-layer membranes of polymers can be achieved through polyion complexes using polycation and polyanion (Fig. 1e). Polycations, such as PAH, PLL, and PEI, are often used as interactive polymers with the cell surface; although, they are cytotoxic. Alginate and PSS and are widely used as polyanions. Several groups have recently tried to construct thin membranes on the surface of cells by the layer-by-layer method. ${ }^{21-25}$ Cell viability was extremely decreased due to the cytotoxicity of the polycations although they succeeded in forming polyelectrolyte multilayer membranes on cell surfaces.

We tried to assemble polymers by disulfide bonding on the cell surface without polyion complex. ${ }^{12}$ A thiol/disulfide exchange reaction between a thiol group and a pyridyl disulfide (PD) group can be used to form a multilayered polymer membrane on the surface. The thiol group is expected to react efficiently with the PD group to form a disulfide bond before autoxidation of the thiol group proceeds. The thiol/disulfide exchange reaction is a mild reaction suitable for the formation of a multilayered 
polymer membrane, without damaging the living cell surface. When the surface was treated alternatively with poly(vinyl alcohol) (PVA) carrying a thiol group (PVA-SH) and PVA-PD, the multilayer of PVA was constructed (Fig. 1e). Since there is no interaction between those polymers and cell surface, the morphology of islets was maintained after surface modification. From a static glucose stimulation test, PVAencapsulated islets released insulin in response to glucose concentration changes, indicating that PVA encapsulation did not impair the insulin-secreting ability of islets. ${ }^{12}$ Thus layer-by-layer method without use of polyion complex is promising because most polycations exert cytotoxicity.

\section{$\underline{\text { 2.5. Bioactive substances immobilized through a intermediary molecule }}$}

The immobilization methods of bioactive substances are summarized in Fig. 1g. There are two classifications of this method. One is immobilization of substances through an intermediary molecule which is covalently bound to membrane proteins on the surface via amide bonding with hetero- or homo-bifunctional cross-linkers. In one example, biotin molecules are covalently bound to the amino groups of membrane proteins via cross-linkers. The surface was then treated with avidin and heparin was immobilized to the surface through an electrostatic interaction with avidin (Isoelectric 
point of avidin; $\mathrm{pI}=10) .{ }^{9}$ Phosphine molecules have also been covalently conjugated to amino groups of membrane proteins to immobilize recombinant thrombomodulin by Staudinger ligation. ${ }^{10}$ The immobilization of serum albumins has been attempted using PEG carrying NHS groups at both ends; one NHS is used for anchoring to the amino group of membrane proteins and the other for the immobilization of serum albumin. ${ }^{11}$ The covalent modification is reported to be no cytotoxic although membrane proteins were chemically modified. $9,10,14$

The other method is formation of an intermediary polymer layer through hydrophobic interaction using amphiphilic polymers such as PEG-lipid and PVA-alkyl carrying various functional groups. ${ }^{15,16}$ The functional groups introduced through the amphiphilic polymers can be used for immobilization of bioactive substances. In one example, PVA-alkyl carrying SH groups is used for immobilization of bioactive substances carrying maleimide groups. By the same means, PEG-lipid carrying maleimide at the end of the PEG chain is also useful for immobilization of bioactive substances carrying SH groups. There is no cytotoxicity after immobilization of proteins to the cell surface.

\section{Addition of supplementary functions on cell surfaces}


Recently, cell surface modification has focused on adding supplementary biological function through cell transplantation, especially islet transplantation for improvement of graft survival. In clinical islet transplantation, islets are transfused into the liver through the portal vein. ${ }^{57,58}$ The islets are lost in the early phase following transplantation, before immune-rejection reaction. The blood coagulation and complement systems are activated by islets and chemotactic factors, tissue factor, chemokines, collagen, and other inflammatory mediators are released during the early post-transplantation phase. An immediate blood mediated inflammatory reaction (IBMIR) is activated, resulting in destruction of the transplanted islets. ${ }^{27-32}$ About $50 \%$ of islets are lost within an hour after transplantation into liver. ${ }^{33}$ In animal studies, thrombin inhibitor Melagatran, ${ }^{34}$ activated protein $\mathrm{C},{ }^{29}$ low molecular weight dextran sulfate, ${ }^{30}$ and the water-soluble domain of complement receptor I (sCR1) have been systematically administered to regulate early coagulation and blood-mediated inflammatory reactions, ${ }^{31,32}$ resulting in a reduction of islets lost. It is difficult, however, to apply these methods in the clinical setting because systemic administration is associated with an increased risk of bleeding. This issue can be avoided by the immobilization of substances having anticoagulant activities to the cell surface for improvement of biocompatibility. 


\subsection{Immobilization of heparin on islets}

The effects of bioactive substances can be localized by the immobilization of such substances on the surface of islets. ${ }^{9,10,15,16}$ Nilsson et al. ${ }^{9}$ proposed coating porcine islets with heparin to inhibit surface thrombosis formation (Fig. 3b). Biotin was covalently immobilized on the surface of porcine islets using activated ester chemistry and the surfaces were further treated with avidin. The islet surface was coated with macromolecular conjugates of heparin, $\sim 70$ heparin molecules covalently linked to an inert carrier chain. In allotransplantation in pigs, increases in plasma concentrations of thrombin-antithrombin (TAT) complexes and complement activation parameter (C3a) were suppressed for heparin-coated islets compared with naïve islets. The transient increase of insulin released from destroyed porcine islets was also suppressed. These results suggest heparinization of the islet surface helps prevent IBMIR.

\subsection{Proteins immobilized on islets}

Chaikof et al. ${ }^{10}$ reported covalently immobilizing recombinant thrombomodulin to the surface of islets. Phosphine molecules were covalently conjugated to amino groups of membrane proteins to anchor recombinant thrombomodulin by Staudinger ligation. The presence of thrombomodulin on the islet surface resulted in a significant increase in the 
production of activated protein $\mathrm{C}$ with a reduction in islet-mediated thrombogenicity.

Covalent immobilization of bioactive substances through membrane proteins is thought to deteriorate membrane protein functions and to perturb cell physiology. ${ }^{3,4}$ Our group developed non-covalent methods for surface modification of islets using various amphiphilic polymers such as PEG-conjugated phospholipid (PEG-lipid) and poly(vinyl alcohol) carrying alkyl chains. ${ }^{12-18}$ Fig. 5b depicts FITC-PEG-lipid modified hamster islets, observed by a confocal laser scanning microscope. Islets are composed of a few thousand cells. Clear fluorescence is seen at the periphery of each islet, indicating the outer cell layer was modified with PEG-lipid, forming a PEG layer on the islet. This method was applied to non-covalently immobilize the fibrinolytic enzyme, urokinase, on the islet surface, as is schematically shown in Fig. $3{ }^{16}$ An amphiphilic PVA derivative carrying long alkyl side chains, thiol, and carboxylic groups was used for immobilization of urokinase on the islet surface. Thiol groups were introduced to the islets surface using amphiphilic PVA derivatives through the hydrophobic interaction between the long alkyl side chains and lipid bilayer of the cell membrane (Fig. 3a). Urokinase was modified with a hetero-bifunctional cross-linker (sulfo-EMCS, $N$-(6Maleimidocaproyloxy) sulfosuccinimide) to introduce maleimide groups. The urokinase carrying maleimide groups was immobilized to the islet surface through the 
maleimide/thiol reaction. Fig. $3 \mathrm{~b}$ shows results from the fibrin plate-based assay.

Urokinase is a serine protease that activates plasminogen to plasmin, which can dissolve fibrin gel. To assess the fibrinolytic activity of the urokinase, urokinase-islets and naive islets (100 islets each) were spotted on a fibrin gel plate and left for 24 hours. The transparent area formed in the fibrin, representing dissolved fibrin, was measured. A large transparent area (diameter; $1.8 \mathrm{~cm}$ ) was observed around the islets carrying urokinase, indicating urokinase activity. The transparent area was small around naïve islet spots. These results suggest immobilization of bioactive substances to the surface of islets is promising and a possible means for improving graft survival following intra portal transplantation.

\section{Masking of cell surface antigens}

When an organ or tissue (the graft) from a donor is transplanted to a patient, the immune system of the patient recognizes the graft as foreign material and attacks and destroys it. In allotransplantion, T cells are activated by recognition of antigens displayed on the surface of the graft. The process initiates the adaptive immune response. In xenotransplantation, hyperacute rejection is induced by pre-existing antibodies to the donor, resulting in a complement-mediated response in recipients. The 
graft is not accepted by the body of the transplant recipient. Masking of the antigens of the graft has been examined to block the immune response to the graft. In this section, we will present some examples where graft functioning periods were prolonged by masking antigens with synthetic polymers.

\subsection{Blood cells}

Surface modification with ultra thin polymer membranes was originally examined in red blood cells (RBC), chemically treated to enclose surface antigens. ${ }^{35-39}$ Camouflaging surface antigens is used to make universal RBC. Methoxy(polyethylene glycol) (mPEG) was covalently bound to the surface of RBC via cyanuric chloride coupling. The reaction site of $\mathrm{mPEG}$ was accessible to the amino groups of lysine residues on membrane proteins. The surface modification of RBC with mPEG was shown to prevent host antibodies from recognizing blood group surface antigens. ${ }^{35-37}$ It was also possible to prevent receptor-ligand interactions by conjugation of mPEG to the surface of human peripheral blood mononuclear cells ${ }^{38}$ and murine splenocytes. ${ }^{39}$ These receptor-ligand interactions involved allorecognition, including weakening CD28-B7 co-stimulation which resulted in T cell apoptosis. 


\subsection{Bioartificial pancreas}

The masking of cell surface antigens has been extensively studied in islet

transplantation and served as the basis for development of a bioartificial pancreas. The concept of a bioartificial pancreas is shown in Fig. 4a. An islet is encapsulated within a semi-permeable membrane. The membrane masks the surface antigens of the islets from the recipient's immune system. Oxygen and nutrients are supplied through the membrane. Insulin, secreted from islets in response to blood glucose increases, can diffuse into the recipient blood circulation through the membrane. It is possible that transplanted islets can survive in the recipient without immuno-suppressive therapy and insulin release from the islets can control glucose metabolism for a long period. The bioartificial pancreas has been studied for over 30 years. ${ }^{40}$ There have been three kinds of bioartificial pancreases including: a diffusion chamber type, hollow fiber type, and microcapsule type. ${ }^{41-48}$ We have found serious problems with the first two types. Islets form large aggregates in chamber and hollow fiber type pancreases. Also, many cells located in the central part of islets are lost due to an insufficient oxygen supply. To prevent this, islets were enclosed within alginate hydrogel and transferred into the device to inhibit contact with each other. In such trials, the size of the device became 
too large to be implanted. Efforts over the past 10 years have focused on the development of the microcapsule type.

\subsubsection{Microencapsulation of islets into hydrogel}

Our group developed a microcapsule type bioartificial pancreas using agarose hydrogel, as shown in Fig. 4b. Hyperglycemia in diabetic mice could be normalized for 200 days after allotransplantation of agarose-encapsulated islets. ${ }^{49-55}$ Yet, the volume of the bioartificial pancreas still restricts its clinical applications. The average diameter of islets is around $150 \mu \mathrm{m}$. The diameter of capsules is about three times as large as the original islets. According to an estimate, the total volume of the microcapsules would be 27 times as large as that of the islets by a 3rd power increase of the radius. In the human clinical setting, $10 \mathrm{~mL}$ of islet suspension would be infused into the portal vein. The volume of the capsule suspension would be greater than $270 \mathrm{~mL}$ and would need to be infused into the liver. We would expect difficulties in infusion of microencapsulated islets into liver through the portal vein or its implantation in other transplantation sites in our body.

Many studies have tried to reduce the size of capsules. Calafiore et al. ${ }^{56}$ reported much smaller microcapsules, i.e. $300 \mu \mathrm{m}$ diameter, which would provide a manageable total 
volume for clinical applications. However, the capsules with larger diameters than the islet itself are expected to plug larger blood vessels, imposing harmful effects on the patient's liver. The diameter of encapsulated islets must be much smaller to allow transplantation of the islets through portal veins. Thus, new methods for the microencapsulation of islets, without increasing the diameter of the implant are necessary.

\subsubsection{Masking the surface antigens of islets with synthetic polymers}

The concept of the bioartificial pancreas was to cover the cell surface with polymer chains or thin membranes to mask the surface antigens (Fig. 5b-d). Several groups originally proposed thin polymer membranes for coverage of the surface of cells and islets, such a PEG molecular and a layer-by-layer membranes of polymers. ${ }^{12,13,15,21}$ Through proper control of PEG chain length and surface grafting density, the cell surface modification with PEG has been shown to camouflage antigenic sites, alter surface charge, and attenuate cell-cell and receptor-ligand interactions. ${ }^{35-39}$ Cationic polymers interact with the negatively charged cell surface and anionic polymers interact with the cationic polymer to form a layer-by-layer membrane by repeated sequential exposure of islet surface to cationic and anionic polymers. 
The activated ester group, $N$-hydroxyl-succinimidyl ester (NHS) group, at the end of PEG (PEG-NHS) has been employed to cover the surface antigen with a PEG layer. It was reacted with the membrane proteins or collagen layer on the islets surface, as in mPEG-RBC. ${ }^{38}$ Byun et al. ${ }^{7,8}$ reported covering the surface of islets with PEG, which reacted with the amino groups of the collagen layer remaining on the islet surface.

Islets (1200) from a Sprague-Dawley rat were transplanted under the kidney capsule of streptozotocin (STZ)-induced diabetic Fisher 344 rats. When naked islets were transplanted without cyclosporine A, an immunosuppressive drug, normoglycemia could not be maintained for more than 5 days. With low doses of cyclosporine A, normoglycemia could be prolonged for up to 12 days. When the surface of islets was modified with PEG-NHS along with a low dose of cyclosporine A, normoglycemia could be maintained for 1 year. It appeared rejection by the host immune system could be effectively suppressed with a combination of PEG and cyclosporine A. Contreras et al. ${ }^{11}$ applied the PEG-NHS modification method to xenogeneic transplantation. There was no change in the morphology of porcine islets and viability after chemical modification with PEG. NHS-PEG-modified porcine islets were transplanted into the liver through the portal vein of NOD-SCID mice. These mice were previously 
transplanted with human lymph cells to establish a human immune-system prior to islet transplantation.

Krol et al. ${ }^{21}$ attempted to encapsulate human pancreatic islets by the layer-by-layer method and found there was minimal loss of islet function and viability when they were coated with a poly(allylamine hydrochloride) $(\mathrm{PAH}) / \mathrm{poly}$ (styrene) sulfate (PSS)/PAH multilayer membrane. However, most cationic polymers, such as poly-L-lysine (PLL) and poly(ethyleneimine), were extremely cytotoxic and severely damaged treated cells. Although a layer-by-layer membrane could be formed on the islet surface using cationic and anionic polyelectrolytes, it was found that direct interaction between the cationic polymer and the cell surface should be avoided or the cell membrane would gradually be destroyed.

Amphiphilic polymers, such as PEG-conjugated phospholipid (PEG-lipid) and poly(vinyl alcohol) carrying alkyl chains, have also been used to mask the surface antigens of islets. ${ }^{12-18}$ Although a confomal PEG layer formed on the cells or islet surface at nanometer levels of thickness (Fig. 5), the PEG layer disappeared from the cell surface approximately 3 days after FACS analysis. ${ }^{14}$ A more stable membrane should be employed for immuno-isolation. To enclosure the whole surface with a stable membrane, a layer-by-layer membrane or a protein layer is further formed on the PEG- 
lipid modified cell surface. Various functional groups, such as maleimide and biotin, are introduced to the end of the PEG chain to be used as reaction points for formation of a layer-by-layer membrane on the cell surface. For example, it is possible to form a layer-by-layer membrane of poly(vinyl alcohol) (PVA) on the islets surface by the reaction between the thiol and maleimide groups. ${ }^{12}$ The islets carrying PEG-lipidmaleimide are exposed to a solution of PVA carrying thiol groups (PVA-SH) (Fig. 1e). A maleimide group reacts with a thiol group to form a stable covalent bond under physiological conditions. A thiol/disulfide exchange reaction between a pyridyldithio group and thiol group can form a third layer on the islets, as shown in Fig. 4c.

A multi-layer membrane can be also formed using a biotin-streptavidin reaction. In our experiments, PEG-lipids carrying biotin at one end of PEG were applied to islets and anchored to the cell membranes. The PEG-lipid layer on the islets was further covered by streptavidin and sequentially treated with bovine serum albumin carrying biotin. This procedure was repeated 20 times (Fig. 5d). ${ }^{15}$ The thickness of the membrane was about $30 \mathrm{~nm}$, based on the calculation from surface plasmon resonance (SPR) analysis. A glucose stimulation test was performed to examine the ability of the modified islets to control insulin release in response to glucose level changes. No significant differences in insulin release were observed between groups of islets with/without surface 
modifications. We also examined the effect of PEG modification on graft survival when islets were transplanted into the liver through the portal vein of STZ-induced diabetic mice. ${ }^{18}$ We found graft survival was improved by surface modification with PEG-lipid and cell damage to islets could be suppressed.

Our group also examined coating the islet surface with an alginate/PLL/alginate multilayer, where $\mathrm{NH}_{2}$-PEG-lipid was introduced into islet cell membranes to form a positively charged islet surface to facilitate electrostatic binding of negatively charged alginate. ${ }^{13}$ The negatively charged surface was sequentially covered with PLL and alginate. Islets coated with this membrane responded normally in a static glucose stimulation assay.

\section{Arrangement of different kinds of cells}

There are various applications of PEG-lipid derivatives in cell biology. For example, when PEG-lipids carrying biotin or oligoDNA sequences are used for cell surface modification, different kinds of cells can be attached or alternatively aligned by specific interactions or hybridization of PEG-lipid derivatives on the surface.

\section{$\underline{\text { 5.1. Alignment of single cells }}$}


Figure 6 shows an example of cell-cell attachment on the cell surface, induced by hybridization of oligoDNA at the end of PEG-lipid. The sequences of oligoDNA were: polyA20: 5'-AAA AAA AAA AAA AAA AAA AA-3' polyT20: 5'-TTT TTT TTT TTT TTT TTT TT-3' PolyA20-PEG-lipid and polyT20-PEG-lipid treated-cells were labeled with PKH red and green, respectively (Fig. 6a). The two kinds of cells were mixed and incubated by rotation culture. Attachment between the two types of cells was observed and gradually they were alternatively aligned as shown in Fig. 6b. Cell aggregates were also observed after 3-hour of rotation culture. In contrast, no attachment was observed between cells not treated with oligoDNA-PEG-lipid, even after 3 hours of rotation culture. These results suggest alternative cell alignment can be induced by hybridization of oligoDNA at the end of PEG-lipid. A biotin-PEG-lipid and streptavidin interaction can also be used to align cells.

The control over the attachment between heterogeneous or homogeneous cells can be a useful tool in the biomedical research field. The technique should be applied to the analysis of cell-cell interaction, the induction of cell fusion, and so on. The analysis of cell-cell interaction is important in stem cell research as hope for embryonic stem (ES) cells and induced pluripotent stem (iPS) cells has increased over the past few 
years. ${ }^{67}$ Methods for regulating the cell-cell interaction should be intensively studied and developed. Cell-cell interactions should be expanded because they might imitate natural embryo development and, thus, are expected to be much more powerful than other methods of ES cell differentiation. In addition, cell fusion has been performed by the use of concentrated poly(ethylene glycol) (PEG) and electrofusion, however, the efficiency of cell fusion should be improved. It would be useful for the formation of hybrodoma for production of monoclonal antibodies. Recently it was reported that somatic cells could be induced into undifferentiated cells by cell fusion with ES cells. ${ }^{68}$ The improvement of cell fusion should be contributed to this research field. Thus the control of cell-cell attachment could be an important technique.

\section{2. Encapsulation of islets with cells}

We recently attempted to encapsulate islets with living cells. ${ }^{17}$ If the surface of islets can be covered with living cells such as vascular endothelial cells or fibroblasts, derived from the recipient, biocompatibility is expected to be significantly improved and the immune-rejection reaction evaded. Therefore, we attempted to microencapsulate islets with a living cell layer membrane. ${ }^{17}$ To our knowledge, there have been no previous reports of microencapsulating islets with living cells. We used amphiphilic PEG-lipid 
and the biotin/streptavidin reaction to immobilize HEK293 cells on the surface of islets, as shown in Fig. 7a. After biotin molecules were introduced on the surface of HEK293 cells by biotin-PEG-lipid, streptavidin was immobilized to the surface. Then biotinPEG-lipid modified islets were mixed with streptavidin-immobilized HEK293 cells. HEK293 cells were immobilized on the islet surface (Fig. 7b). The surface of the islets was completely covered with a cell layer after 3 to 5 days in culture without central necrosis of the islet cells (Fig. 7c and d). Insulin secretion was well maintained upon glucose stimulation of HEK293 cell-encapsulated islets. We were successful in microencapsulating islets with a cell layer, although HEK293 cells are a cell line. We are trying to microencapsulate islets with human vascular endothelial cells using the same technique.

Islets are exposed to fresh blood when they are transfused into the liver through the portal vein. The coagulation and complement systems are activated by the islet surface during the early post-transplantation phase, leading to the release of chemotactic factors, tissue factor, chemokines, and other inflammatory mediators. The transplanted islets are destroyed by the innate immune reactions. ${ }^{27}$ Therefore, the new idea to overcome these issues is the encapsulation of islet with endothelial cells to suppress blood-mediated inflammatory reactions because the surface of endothelial cells is inert to blood. We 
believe our technique can be useful to suppress some inflammatory reactions after islet

transplantation into liver through portal vein in the current clinical protocol.

\section{3. Control lineages of embryonic stem cells by cell-cell interaction}

The attachment of different kinds of cells, including single cells and cell aggregates, can be successfully induced by surface modification with PEG-lipid carrying biotin and streptavidin or complementary DNA sequences. With these techniques, we have induced intimate cell-cell contact between mouse embryonic stem (ES) cells and feeder cells. The lineage fate of ES cells is thought to be determined by cell-cell interactions (H. Iwata et al Biomaterials, submitted). We analyzed the neuronal differentiation of ES cells by immunostaining over time. We used HEK293 cells (human endoderm kidney cell line) and PA6 cells (PA6 cells derived from skull bone marrow) as feeder cells. HEK293 cells, genetically modified to express green fluorescent protein, were immobilized on the embryoid body (EB) surface, an aggregate of mouse ES cells. The cells uniformly attached and spread onto the EBs, proliferating to cover the whole surface of the EBs (Fig. 8). PA6 cells (labeled with Cell Tracker Green) initially attached uniformly to the EBs; yet, they could not cover the EB surface completely. HEK293 and PA6 cells were expected to exert different effects on ES cells in EBs. The 
frozen sections of EBs, treated with these two kinds of cells, were analyzed by immunostaining against neuron markers, Nestin and TuJ1 (lower panels in Fig. 8). Anti-Nestin and TuJ1 antibodies were used to find neural progenitor cells and mature neurons, respectively, in the EBs. Nestin stained red, TuJ1 stained green, and the nuclei were stained with Hoechst blue (Fig. 8). The ES cells were promoted to differentiate into neural cells when PA6 cells were immobilized on the EB surface. Strong expression of Nestin and TuJ1 was found locally at the parts of the EBs where PA6 cells were attached. In contrast, contact interaction with HEK293 cells completely suppressed the neuronal differentiation of ES cells. These results suggest our method, using biotinPEG-lipid and streptavidin, is promising for studying the effects of intercellular contact interactions on the differentiation of ES cells. Although the results presented here are preliminary, we expect the application of this technology to stem cell research and embryology will be of much interest to the area of cell biology.

\section{Conclusion and perspective}

The application of cell surface modification to cell transplantation will have a strong impact on the therapies of various endocrine diseases. Its effectiveness has been demonstrated using animal models suffering from type I diabetes, as discussed in 
relation to the bioartificial pancreas. The same technologies can be applicable to disorders of the central nervous system such as Parkinson's, Alzheimer's, ALS, and Huntington's disease because it is necessary to prevent the graft loss from the attack by immune-rejection reaction. ${ }^{59-66}$ It is also considered that the early graft loss should be serious problem which indicates that the most transplanted cells would be lost before immune-rejection. As we already mentioned, transplanted cells are destroyed by the innate immune reactions which are activated by coagulation and complement systems when cells are exposed to fresh blood. Therefore, it is important to modify the cell surface with biocompatible polymers, bioactive substances, and living cells derived from patients to suppress the graft loss not only from the innate immune reactions but also from immune-rejection reaction. Our surface modification methods described here can be applied to the all kinds of cells for transplantation and have a potential for improvement of graft survival. Also for our conformal coating method, there is no volume increase, indicating that the same clinical protocol of transplantation can be applied after the surface modification.

Clinical applications of the technology are mainly restricted by the shortage of cells from human donors. However, various functional cells have been derived from human ES cells. In addition, Yamanaka et al. ${ }^{67}$ developed a method to obtain induced 
pluripotent stem (iPS) cells from a patient's skin cells, which have pluripotency as ES cells. Sufficient numbers of these pluripotent stem cells will be obtained in the near future and the technology of cell surface modification will be successfully applied to treat human patients. However, for treatment of autoimmune disease such as type I diabetes, it is also necessary to suppress the immune reactions although cells were obtained from patients because autoimmune disease is to attack autologous cells. For this case, it is important to modify the cell surface to suppress the immune reactions. Our review is summarized as follows. The cell surface modification methods are classified into three categories: (1) covalent conjugation to amino groups of cell surface proteins, (2) electrostatic interaction between cationic polymers and a negatively charged surface, and (3) incorporation of amphiphilic polymers into the lipid bilayer membrane of cells by hydrophobic interaction as summarized in Fig. 2. However, the use of cationic polymers is difficult for cell surface modification because they are generally cytotoxic to most cells through the method (2). The method (1) and (3) are appropriate for cell surface modification due to no cytotoxicity. For these methods, the stability of polymers on the cell surface is almost the same. The difference between these methods is covalent conjugation to membrane proteins or hydrophobic insertion into membrane. It is possible to immobilize bioactive substances to the cell surface and 
to form layer-by-layer membrane on the surface through these methods. Conformal coating of cells for transplantation can be achieved through covalent conjugation or hydrophobic interaction. These methods are promising for improvement of graft survival. Thus the surface modification by covalent conjugation is useful, however, there is a potential for denaturation membrane proteins due to the chemical modification of membrane and cytoplasmic proteins. And the potential of functional groups is limited because there are no varieties of available hetero-bifunctional cross-linkers. On the other hand, there is no chemical modification to membrane proteins and cells for surface modification by hydrophobic interaction. And it is easy to introduce various functional groups including DNA by using PEG-lipid derivatives because the end group of PEG chain is available for chemical modification. Several different types of groups can be also introduced to the surface to expand in biomedical application. Cell surface modification can be also applied to various biomedical research, such as cell-cell interaction analysis, cell arrangement, lineage determination of stem cells, and many others as we showed in Fig. 6, 7, and 8. Although there is more work to be completed in this new research area, this new technology will allow for future advances in biomedical engineering and science. 


\section{References}

1. S. Kizilel, M. Garfinkel, and E. Opara. Diabetes Technol Ther, 2005, 7, 968-985.

2. J. T. Wilson, and E. L. Chaikof. Adv Drug Deliv Rev, 2008, 60, 124-145.

3. E. Saxon, and C. R. Bertozzi. Science, 2000, 287, 2007-2010.

4. J. A. Prescher, D. H. Dube, and C. R. Bertozzi, Nature, 2004, 430, 873-877.

5. D. Rabuka, M. B. Forstner, J. T. Groves, and C. R. Bertozzi. J Am Chem Soc, 2008, 130, 5947-5953.

6. M. G. Paulick, M. B. Forstner, J. T. Groves, and C. R. Bertozzi. Proc Natl Acad Sci U S A, 2007, 104, 20332-20337.

7. D. Y Lee, J. H. Nam, and Y. Byun. Biomaterials, 2007, 28, 1957-1966.

8. D. Y Lee, S. Lee, J. H. Nam, and Y. Byun. Am J Transplant, 2006, 6, 1820-1828.

9. S. Cabric, J. Sanchez, T. Lundgren, A. Foss, M. Felldin, R. Kallen, K. Salmela, A. Tibell, G. Tufveson, R. Larsson, O. Korsgren, and B. Nilsson. Diabetes, 2007, 56, 2008-2015.

10. C. L. Stabler, X. L. Sun, W. Cui, J. T. Wilson, C. A. Haller, and E. L. Chaikof. Bioconjugate Chem, 2007, 18, 1713-1715. 
11. J. L. Contreras, D. Xie, J. Mays, C. A. Smyth, C. Eckstein, F. G. Rahemtulla, C. J. Young, J. T. Anthony, G. Bilbao, D. T. Curiel, and D. E. Eckhoff. Surgery, 2004, 136, 537-547.

12. Y. Teramura, Y. Kaneda, and H. Iwata. Biomaterials, 2007, 28, 4818-4825.

13. S. Miura, Y. Teramura, and H. Iwata. Biomaterials, 2006, 27, 5828-5835.

14. Y. Teramura, Y. Kaneda, T. Totani, and H. Iwata. Biomaterials, 2008, 29, $1345-$ 1355

15. Y. Teramura, and H. Iwata. Bioconjugate Chem, 2008, 19, 1389-1395.

16. T. Totani, Y. Teramura, and H. Iwata, Biomaterials, 2008, 29, 2878-2883.

17. Y. Teramura, and H. Iwata. Biomaterials, 2009, 30, 2270-2275.

18. Y. Teramura, and H. Iwata. Transplantation, 2009, 88, 624-630.

19. S. Zalipsky. Bioconjugate Chem, 1995, 6, 150-165.

20. A. L. Klibanov, K. Maruyama, V. P. Torchilin, and L. Huang. FEBS Lett, 1990, 268, 235-237.

21. S. Krol, S. del Guerra, M. Grupillo, A. Diaspro, A. Gliozzi, and P. Marchetti. Nano Lett, 2006, 6, 1933-1939.

22. D.L. Elbert, C.B. Herbert, and J.A. Hubbell, Langmuir, 1999, 15, 5355-5362. 
23. M. Chanana, A. Gliozzi, A. Diaspro, I. Chodnevskaja, S. Huewel, V. Moskalenko,

K. Ulrichs, H.J. Galla, and S. Krol, Nano. Lett. 2005, 5, 2605-2612.

24. M. Germain, P. Balaguer, J.C. Nicolas, F. Lopez, J.P. Esteve, G.B. Sukhorukov, M.

Winterhalter, and H. Richard-Foy. Biosens. Bioelectron. 2006, 21, 1566-1573.

25. N.G. Veerabadran, P.L. Goli, S.S. Stewart-Clark, Y.M. Lvov, and D.K. Mills, Macromol. Biosci, 2007, 7, 877-882.

26. G. Decher, Science, 1997, 277, 1232-1237.

27. O. Korsgren, T. Lundgren, M. Felldin, A. Foss, B. Isaksson, J. Permert, N. H. Persson, E. Rafael, M. Rydén, K. Salmela, A. Tibell, G. Tufveson, and B. Nilsson. Diabetologia, 2008, 51, 227-232.

28. L. Moberg, H. Johansson, A. Lukinius, C. Berne, A. Foss, R. Kallen, O. Ostraat, K. Salmela, A. Tibell, G. Tufveson, G. Elgue, K. Ekdahl, O. Korsgren, B. Nilsson, Lancet, 2002, 360, 2039-2045.

29. J. L. Contreras, C. Eckstein, C. A. Smyth, G. Bilbao, M. Vilatoba, S. E. Ringland, C. Young, J. A. Thompson, J. A. Fernandez, J. H. Griffin, and D. E. Eckhoff, Diabetes, 2004, 53, 2804-2814. 
30. H. Johansson, A. Lukinius, L. Moberg, T. Lundgren, C. Berne, A. Foss, M. Felldin,

R. Kallen, K. Salmela, A. Tibell, G. Tufveson, K. N. Ekdahl, G. Elgue, O. Korsgren,

B. Nilsson, Diabetes, 2005, 54, 1755-1762.

31. W. Bennet, B. Sundberg, T. Lundgren, A. Tibell, C. G. Groth, A. Richards, D. J.

White, G. Elgue, R. Larsson, B. Nilsson, and O. Korsgren, Transplantation, 2000,

69, 711-719.

32. W. Bennet, B. Sundberg, C. G. Groth, M. D. Brendel, D. Brandhorst, H. Brandhorst,

R. G. Bretzel, G. Elgue, R. Larsson, B. Nilsson, and O. Korsgren. Diabetes, 1999,

48, 1907-1914.

33. T. Eich, O. Eriksson, A. Sundin, S. Estrada, D. Brandhorst, H. Brandhorst, B.

Langstrom, B. Nilsson, O. Korsgren, and T. Lundgren. Transplantation, 2007, 84, 893-898.

34. L. Ozmen, K. N. Ekdahl, G. Elgue, R. Larsson, O. Korsgren, and B. Nilsson, Diabetes, 2002, 51, 1779-1784.

35. M. D. Scott, K. L. Murad, F. Koumpouras, M. Talbot, and J. W. Eaton. Proc Natl Acad Sci U S A, 1997, 94, 7566-7571.

36. S. Hashemi-Najafabadi, E. Vasheghani-Farahani, S.A. Shojaosadati, M.J. Rasaee, J.K. Armstrong, M. Moin, and Z. Pourpak, Bioconjug. Chem. 2006, 17, 1288-1293. 
37. P. Nacharaju, F.N. Boctor, B.N. Manjula, and S.A. Acharya, Transfusion, 2005, 45, $374-383$.

38. K.L. Murad, E.J. Gosselin, J.W. Eaton, and M.D. Scott, Blood, 1999, 94, 21352141.

39. A.M. Chen, and M.D. Scott, J. Biomed. Mater. Res., A. 2003, 67, 626-636.

40. J. Archer, R. Kaye, and G. Mutter. J. Surg. Res. 1980, 28, 77-85.

41. F. Lim F and A. M. Sun, Science, 1980, 210, 908-910.

42. A. S. Narang, and R. I. Mahato. Pharmacol Rev. 2006, 58, 194-243.

43. G. M. O’Shea, M. F. A. Goosen, A. M. Sun, Biochim Biophys Acta. 1984, 804, 133-136.

44. P. Grohn, G. Klock, J. Schmitt, U. Zimmermann, A. Horcher, R. G. Bretzel, B. J. Hering, D. Brandhorst, H. Brandhorst, T. Zekorn, et al. Exp Clin Endocrinol. 1994, 102, 380-387.

45. Y. L. Sun, X. J. Ma, D. B. Zhou, I. Vacek, A. M. Sun. J. Clin Invst. 1996, 98, 14171422.

46. S. Hirotani, R. Eda, T. Kawabata, S. Fuchinoue, S. Teraoka, T. Agishi, and H. Ohgawara. Cell Transplant. 1999, 8, 399-404. 
47. S. H. Lee, E. Hao, A. Y. Savinov, I. Geron, A. Y. Strongin, and P. Itkin-Ansari.

Transplantation, 2009, 87, 983-991.

48. P. E. Lacy, O. D. Hegre, A. Gerasimidi-Vazeou, F. T. Gentile, and K. E. Dionn.

Science, 1991, 254, 1782-1784.

49. H. Iwata, T. Takagi, H. Amemiya, H. Shimizu, K. Yamashita, K. Kobayashi, and T Akutsu. J. Biomed. Mater. Res, 1992, 26, 967-977.

50. H. Iwata, K. Kobayashi, T. Takagi, T. Oka, H. Yang, H. Amemiya, T. Tsuji, and F. Ito, J. Biomed. Mater. Res., 1994, 28, 1003-1011.

51. H. Iwata, T. Takagi, K. Kobayashi, T. Oka, T. Tsuji, and F. Ito, J Biomed Mater Res, 1994, 28, 1201-1207.

52. T. Kin, H. Iwata, Y. Aomatsu, T. Ohyama, H. Kanehiro, M. Hisanaga, and Y. Nakajima. Pancreas, 2002, 25, 94-100.

53. T. Kobayashi, Y. Aomatsu, H. Iwata, T. Kin, H. Kanehiro, M. Hisanaga, S. Ko, M. Nagao, and Y. Nakajima, Transplantation, 2003, 75, 619-625.

54. C. A. Agudelo and H. Iwata, Biomaterials, 2008, 29, 1167-1176.

55. C. A. Agudelo Y. Teramura, and H. Iwata Transplantation, 2009, 87, $29-34$.

56. R. Calafiore, G. Basta, G. Luca, C. Boselli, A. Bufalari, A. Bufalari, M. P. Cassarani, G. M. Giustozzi, and P. Brunetti, Ann N Y Acad Sci. 1999, 875, 219-232. 
57. A. M. Shapiro, J. R. Lakey, E. A. Ryan, G. S. Korbutt, E. Toth, G. L. Warnock, N.

M. Kneteman, and R. V. Rajotte, N. Engl. J. Med, 2000, 343, 230-238.

58. E. A. Ryan, J. R. Lakey, R. V. Rajotte, G. S. Korbutt, T. Kin, S. Imes, A.

Rabinovitch, J. F. Elliott, D. Bigam, N. M. Kneteman, G. L. Warnock, I. Larsen, A.

M. Shapiro, Diabetes, 2001, 50, 710-719.

59. M. Lohr, A. Hoffmeyer, J. Kroger,M. Freund, J. Hain, A. Holle, P. Karle, W.T.

Knofel, S. Liebe, P. Muller, H. Nizze, M. Renner, R.M. Saller, T. Wagner, K.

Hauenstein,W.H. Gunzburg, and B. Salmons, Lancet , 2001, 357, 1591-1592.

60. K.C.Wollert, and H. Drexler, Curr. Opin. Cardiol. 2006, 21, 234-239.

61. T. Visted, R. Bjerkvig, and P.O. Enger, Neuro. Oncol. 2001, 3, 201-210.

62. S. Prakash, and T.M. Chang, Nat. Med, 1996, 2, 883-887.

63. M.S. Shoichet, and S.R. Winn, Adv. Drug Deliv. Rev, 2000, 42, 81-102.

64. D.F. Emerich, and S.R. Winn, Crit. Rev. Ther. Drug Carrier. Syst, 2001, 18, 265298.

65. S. Hao, L. Su, X. Guo, T. Moyana, and J. Xiang, Exp. Oncol, 2005, 27, 56-60.

66. M.K. Lee, and Y.H. Bae, Adv.Drug Deliv. Rev. 2000, 42, 103-120.

67. K. Takahashi, K. Tanabe, M. Ohnuki, M. Narita, T. Ichisaka, K. Tomoda, and S. Yamanaka. Cell, 2007, 131, 861-872. 
68. Matsumura H, Tada T. Cell fusion-mediated nuclear reprogramming of somatic cells. Reprod Biomed Online. 2008 16:51-56 


\section{Figure Captions}

Figure 1. Cell surface modification with synthetic polymers. Chemical structure of (a) poly(ethylene glycol) (PEG), (b) PEG carrying $N$-hydroxyl-succinimidyl ester (PEGNHS), (c) PEG-conjugated phospholipid (PEG-lipid) and poly(vinyl alcohol) carrying side alkyl chains (PVA-alkyl), (d) poly(ethyleneimine) (PEI), and (e) poly(allylamine) (PAA), poly(styrene) sulfate (PSS), PVA derivative (PVA-SH, PVA-PD). (f)

Schematic illustration of surface modification of a cell with synthetic polymers by covalent bonding, hydrophobic interaction, electrostatic interaction, and the layer-bylayer method. (g) Schematic illustration of the immobilization of bioactive substances to the cell surface via polymers.

Figure 2. Cell surface modification with amphiphilic PEG-lipid. (a) Chemical structure of PEG-lipid derivatives, $\mathrm{R}$ is a functional group such as an amino group, biotin, maleimide group, or oligo DNA. Schematic illustration shows the interaction between PEG-lipid and the lipid bilayer of a cell membrane. (b) Real-time monitoring of incorporation of PEG-lipid into a supported lipid membrane by a surface plasmon resonance (SPR) instrument. Suspension of a small unilamellar vesicle of egg york lecithin $(70 \mu \mathrm{g} / \mathrm{mL})$ was applied to a methyl-terminated self-assembly monolayer $\left(\mathrm{CH}_{3^{-}}\right.$ 
SAM) surface. A PEG-lipid solution $(100 \mu \mathrm{g} / \mathrm{mL})$ was then applied. Here we used three kinds of PEG-lipids with different length acyl chains; PEG-DMPE, PEG-DPPE, and PEG-DSPE have 14, 16, and 18 carbons, respectively, in an acyl chain. (c) Observation of FITC-labeled PEG-lipid modified CCRF-CEM cells by a confocal laser scanning microscope The fluorescence of FITC was observed at the periphery of all cells, indicating PEG-lipids are anchoring to the lipid bilayer membrane of the cell surface by hydrophobic interaction.

Figure 3. Immobilization of urokinase on the surface of islets. (a) Immobilization of urokinase to the islet surface using amphiphilic PVA-alkyl. (b) Fibrin plate assay of urokinase-immobilized islets. Urokinase-immobilized islets and non-treated islets (100 islets each) were placed on a fibrin gel plate and incubated at $37^{\circ} \mathrm{C}$ for $13 \mathrm{~h}$. A large transparent area formed around the urokinase-immobilized islets due to dissolution of the fibrin gel by plasmin, which is produced from plasminogen by urokinase.

Figure 4. Bioartificial pancreas. (a) The concept of an immuno-isolation membrane.

(b) Enclosure of islets in agarose microcapsules. 
Figure 5. Photos of surface modification of cells (CCRF-CEM) and enclosure of islets with thin polymer membranes via PEG-lipid derivatives, taken by a confocal laser scanning microscope. (a) FITC-PEG-lipid modified CCRF-CEM cells. (b) FITC-PEGlipid modified islets. (c) Layer-by-layer membrane of PVA-coated islets. PVA was labeled with FITC. (d) Layer-by-layer membrane of biotin-BSA and FITC-streptavidincoated islets.

Figure 6. Alignment of single cells by interactions between complementary oligoT and oligoA, introduced on different cell surfaces. (a) Chemical structure of oligoDNAPEG-lipid and oligoDNA sequences (polyA20 and polyT20). (b) Alignment of single cells. PolyA20 and polyT20 cells are labeled with PKH red and PKH green, respectively. The cell attachment was induced by hybridization between polyA20 and polyT20 attached to PEG-lipid on the cell surface.

Figure 7. Encapsulation of islets with living cells. (a) Schematic illustration depicting how to enclose an islet with living cells utilizing the avidin and biotin interaction. (b) Hamster islets modified with biotin-PEG-lipid were immobilized with streptavidinimmobilized HEK293 cells. HEK293 cells were labeled with CellTracker®. (c) Phase 
contrast microscopic images of islets carrying HEK293 cells and histochemical analyses (HE staining and immunostaining) of HEK293 cells-immobilized islets in culture. (c)lower right; Alexa 488-labeled anti-insulin antibody and Hoechst 33342 dye for nuclear staining. The pictures are merged images from insulin and Hoechst 33342 staining. (d) GFP-expressing HEK293 encapsulated islets observed at 3 days culture and their sliced section at 3 days.

Figure 8. Immunocytochemical analyses of EBs carrying GFP-HEK293 and PA6 cells after 6 days of hanging drop culture. Untreated EBs were used as controls. GFP-HEK and PA6 cells labeled with PKH67 (green) were used. Upper panels show the confocal laser scanning images. Frozen sample sections (lower panels) were stained with antibodies for Nestin (red) and TuJ1 (green), which are markers of neural progenitor cells and mature neurons, respectively. Hoechst 33342 dye (blue) was used for nuclear staining. The pictures are merged images from Nestin, TuJ1, and Hoechst 33342 staining. The arrows indicate the local expression of Nestin and TuJ1. 


$$
\text { PEG : } \longrightarrow\left(\mathrm{CH}_{2}-\mathrm{CH}_{2}-\mathrm{O}\right)_{\mathrm{n}}-
$$

(b) Covalently bonding<smiles>COCCOCCCC(=O)ON1C(=O)CCC1=O</smiles>

\section{PEG-NHS}

(c) Hydrophobic interaction

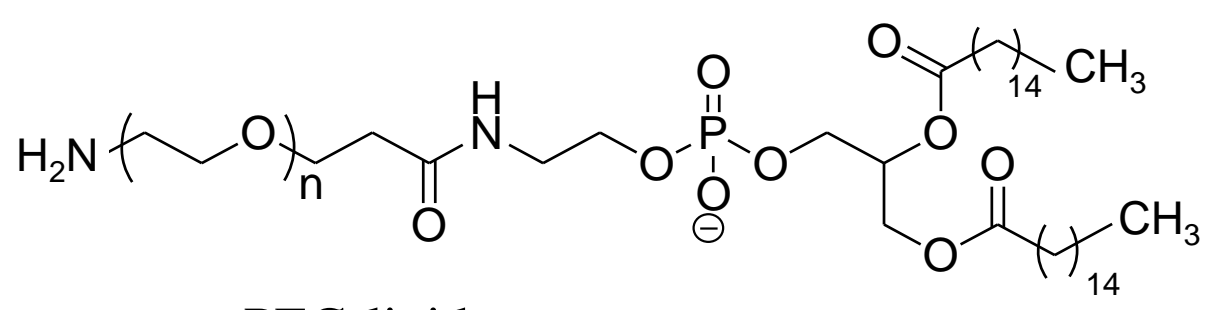

PEG-lipid

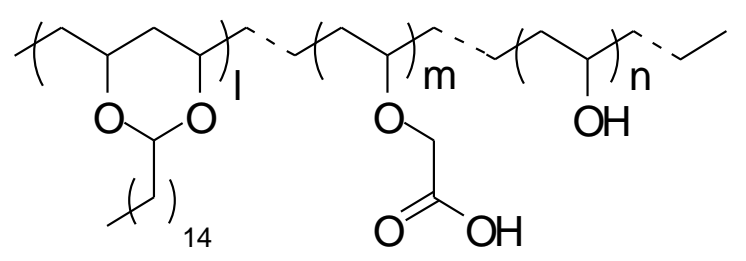

PVA-alkyl

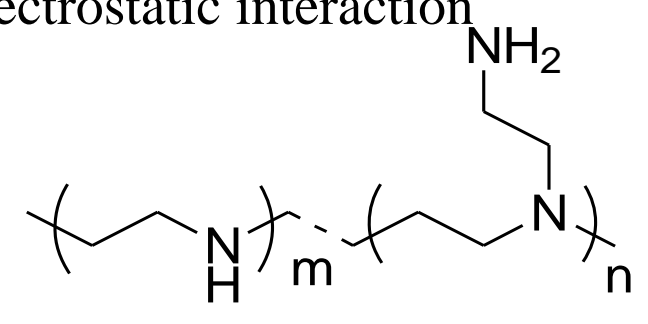

PEI

(e) Layer-by-layer method

Polyion complex<smiles>CC(C[NH3+])CC(C)(C)C</smiles><smiles>CC(C)(C)CC(c1ccc(S(=O)(=O)[O-])cc1)C(C)(C)C</smiles>

PAA

Disulfide bonding

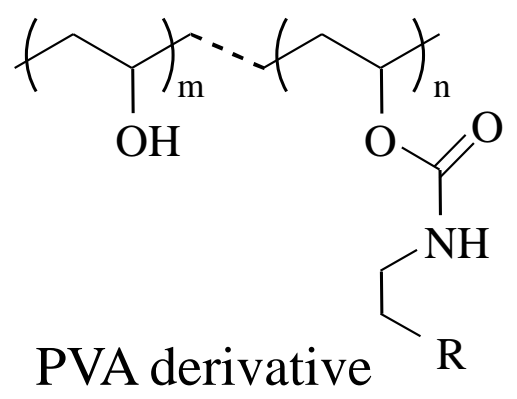

$\begin{array}{lc}\text { PVA-SH } & \mathrm{R}:-\mathrm{SH} \\ \text { PVA-PD } & :-\mathrm{S}-\mathrm{S}-\square\end{array}$ 


\section{2. 京都大学}

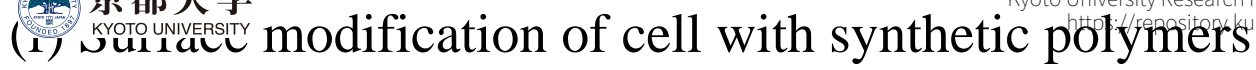

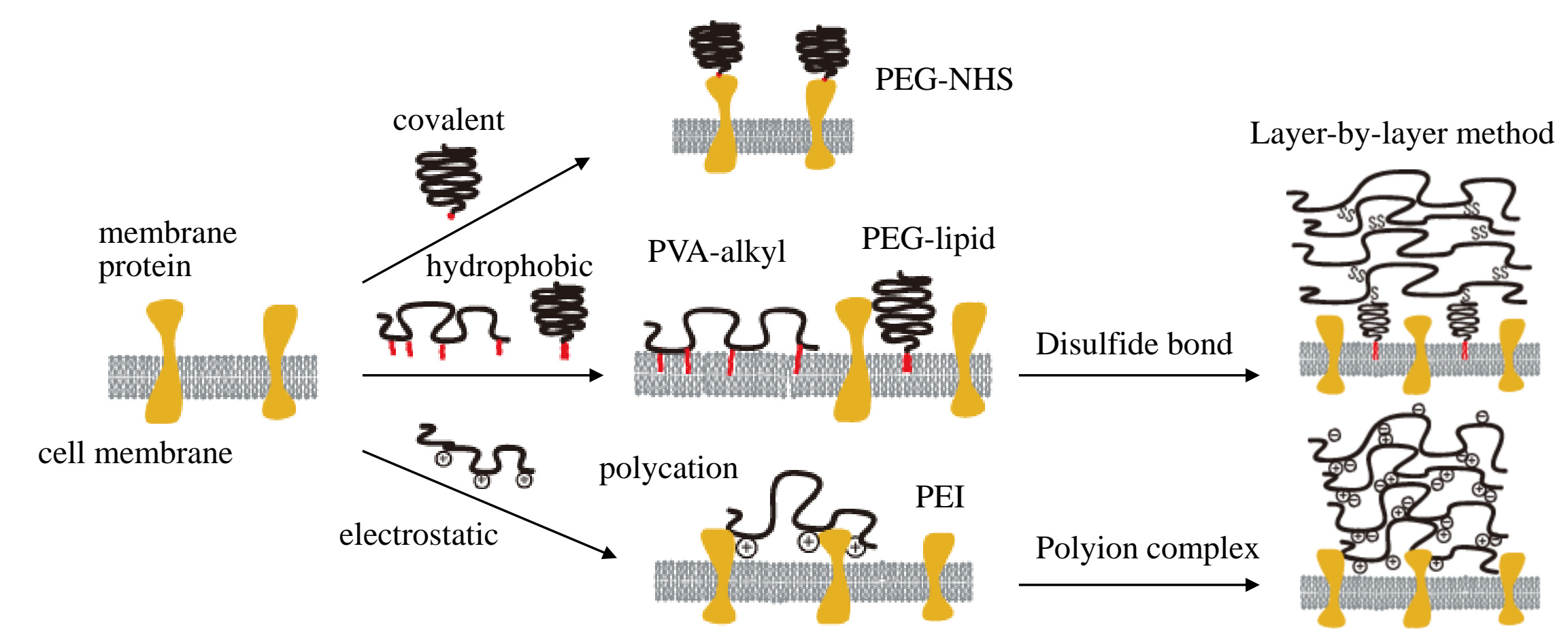

(g) Immobilization of bioactive substances

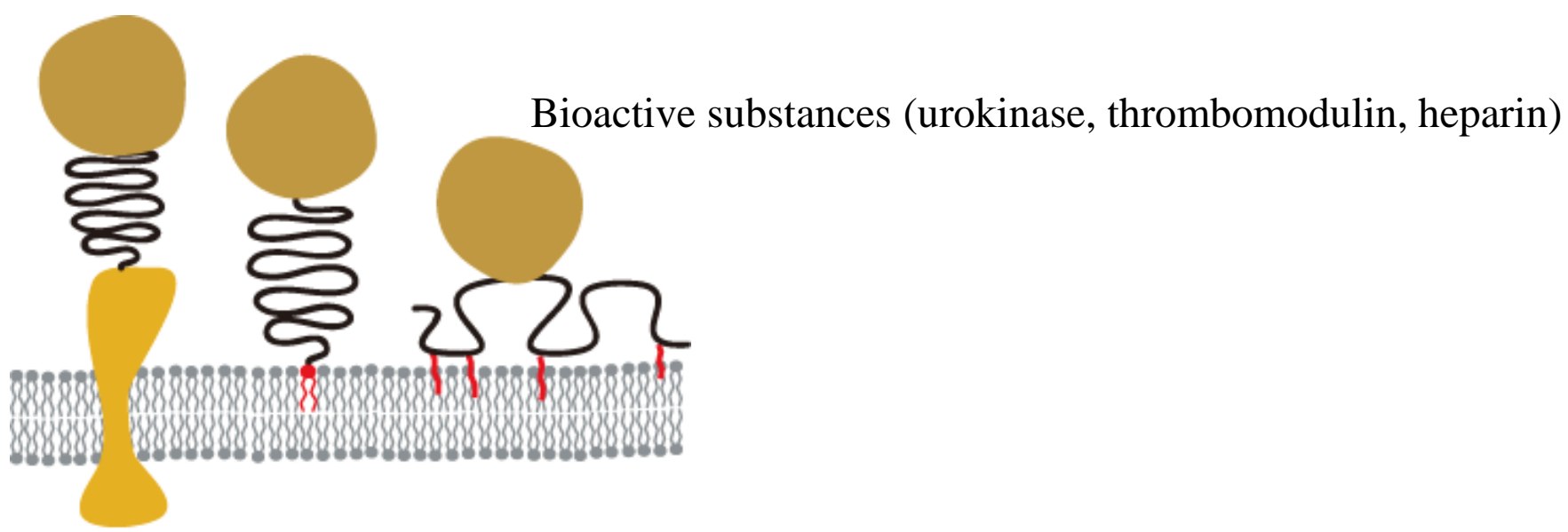


<smiles>[R]CCC(=O)NCCOCCC(=O)NCCOP(=O)([O-])OCC(COC(=O)NCC)OC(=O)CC</smiles>

Incorporation into membrane (hydrophobic)
Anchoring to cell surface (hydrophilic)
Functional group

(R: amine, maleimide, biotin, oligo DNA)

(b) Real-time monitoring of incorporation of PEG-lipid into supported lipid membrane by SPR

i) Formation of supported lipid membrane

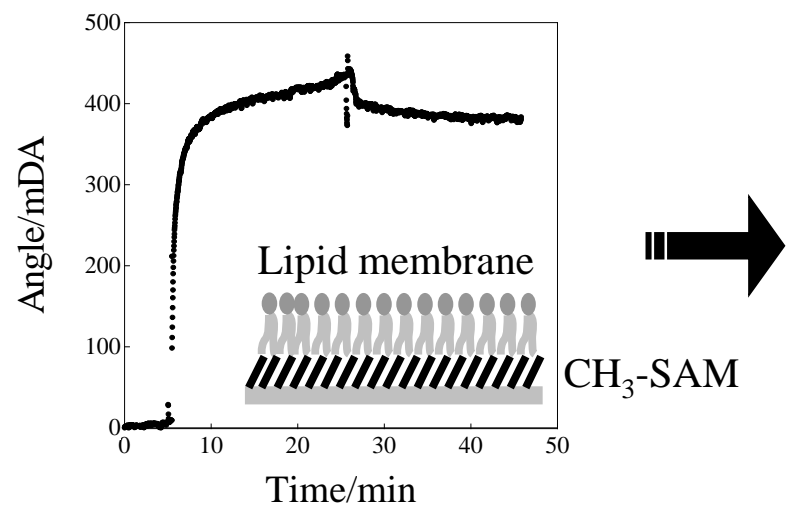

ii) Incorporation of PEG-lipids $(100 \mu \mathrm{g} / \mathrm{mL})$

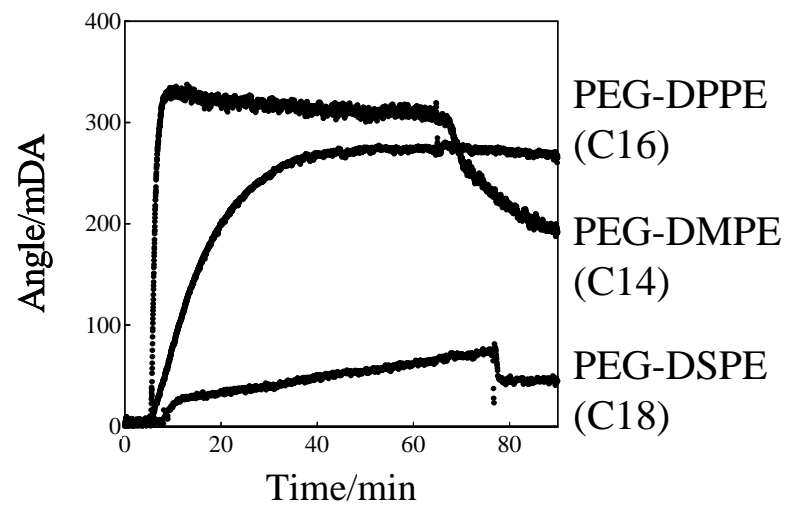

Cell

membrane

(c) Observation of cell surface modification by a confocal laser scanning microscopy

scanned view area

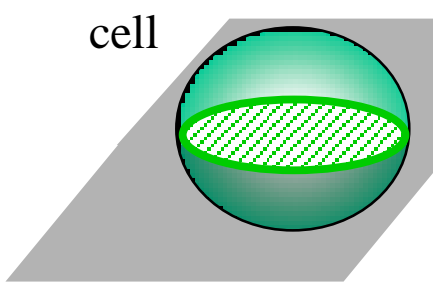

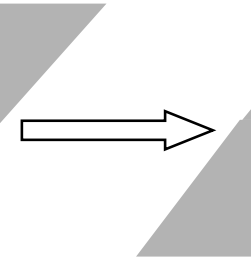
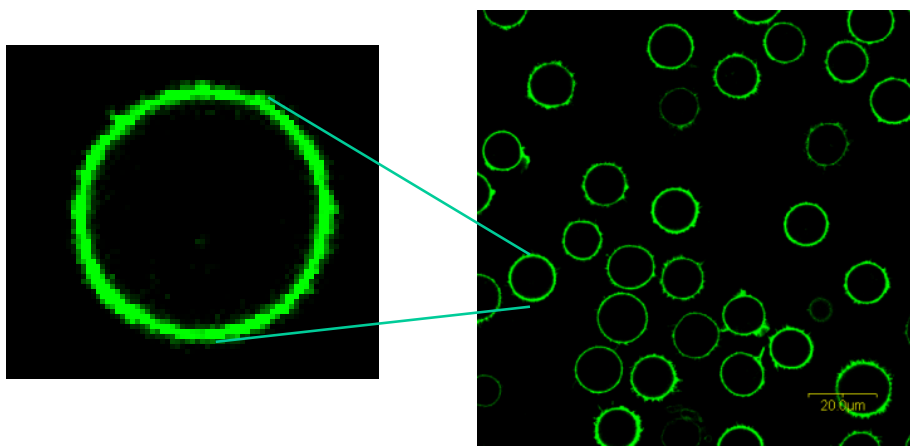

PEG-lipid

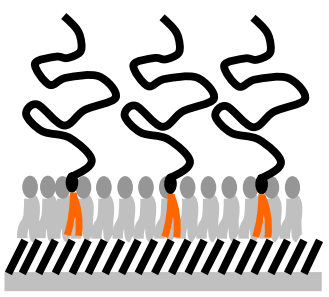


(a)

\section{PVA derivative}<smiles>CCCC(C)C(C)(C)C(C)(C)CC(OCC(=O)O)C(C)(C)C(C)(C)CC1CC(C(C)(C)CC2CC2)OC(C(C)(C)CC(C)C)O1</smiles>
Urokinase-Mal

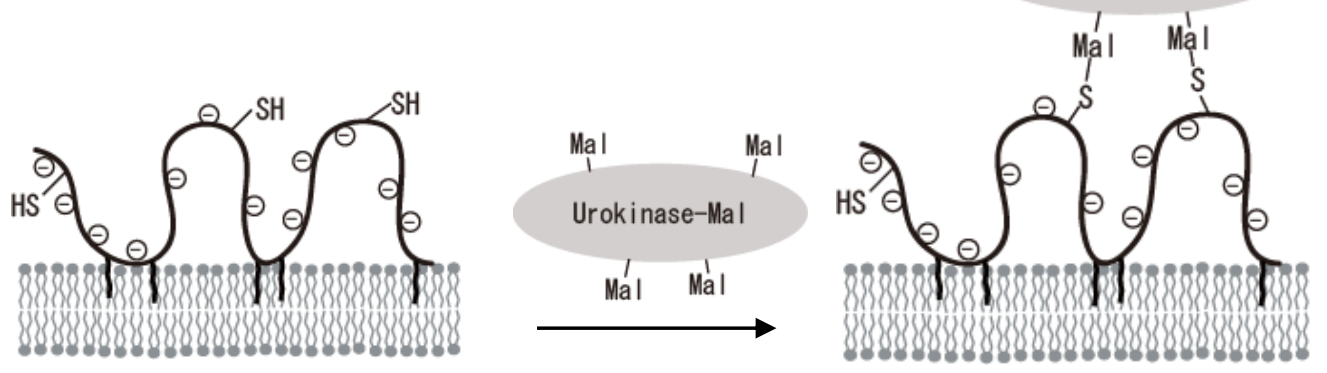

(b)

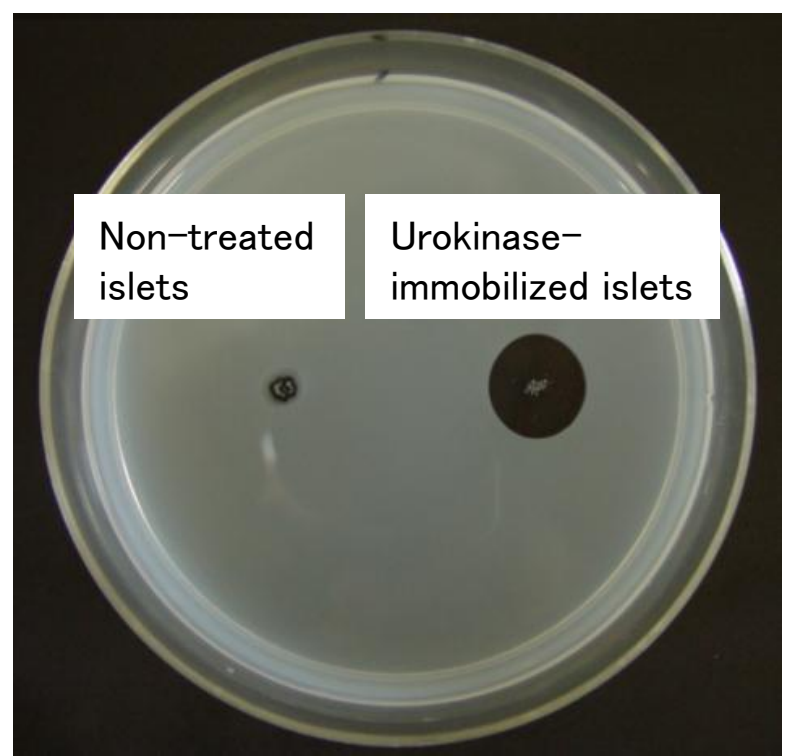

Figure 3 
(a) Concept of immuno-isolation membrane immunocompetent cells, antibody, complement

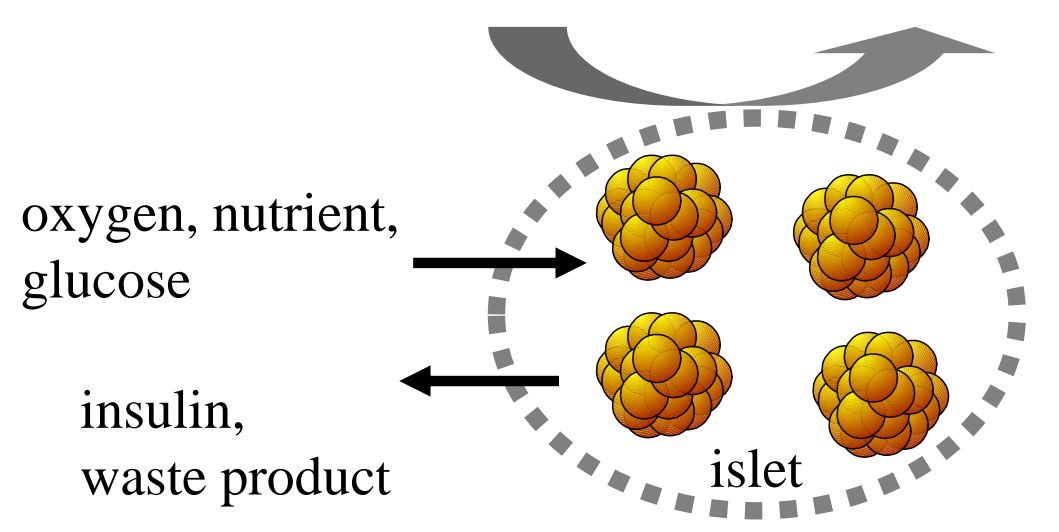

Semi-permeable membrane (b) Agarose-encapsulated islets

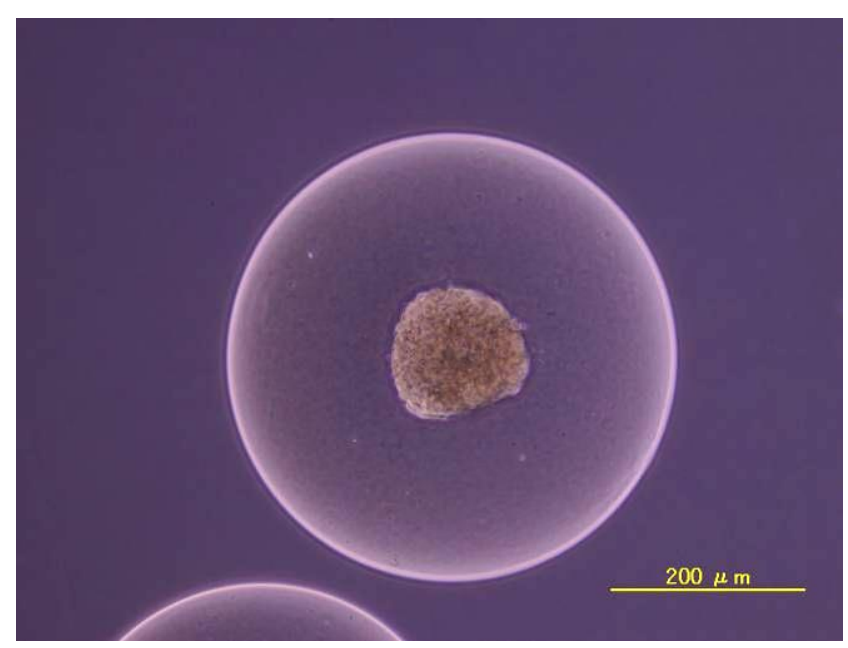

Figure 4 
(a)

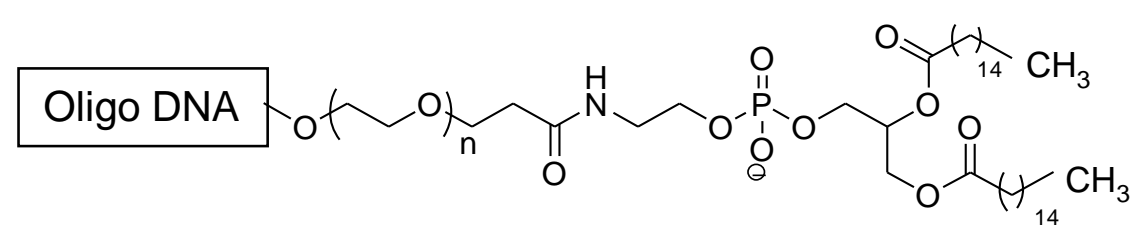

Oligo DNA : AAAAAAAAAAAAAAAAAAAA (polyA20) : TTTTTTTTTTTTTTTTTTTTT (polyT20)

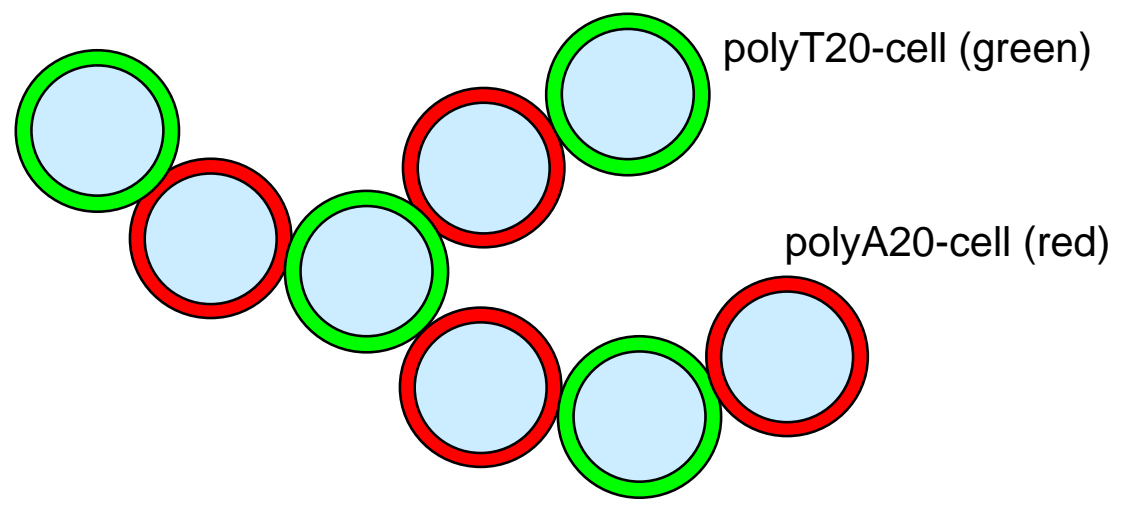

(b)

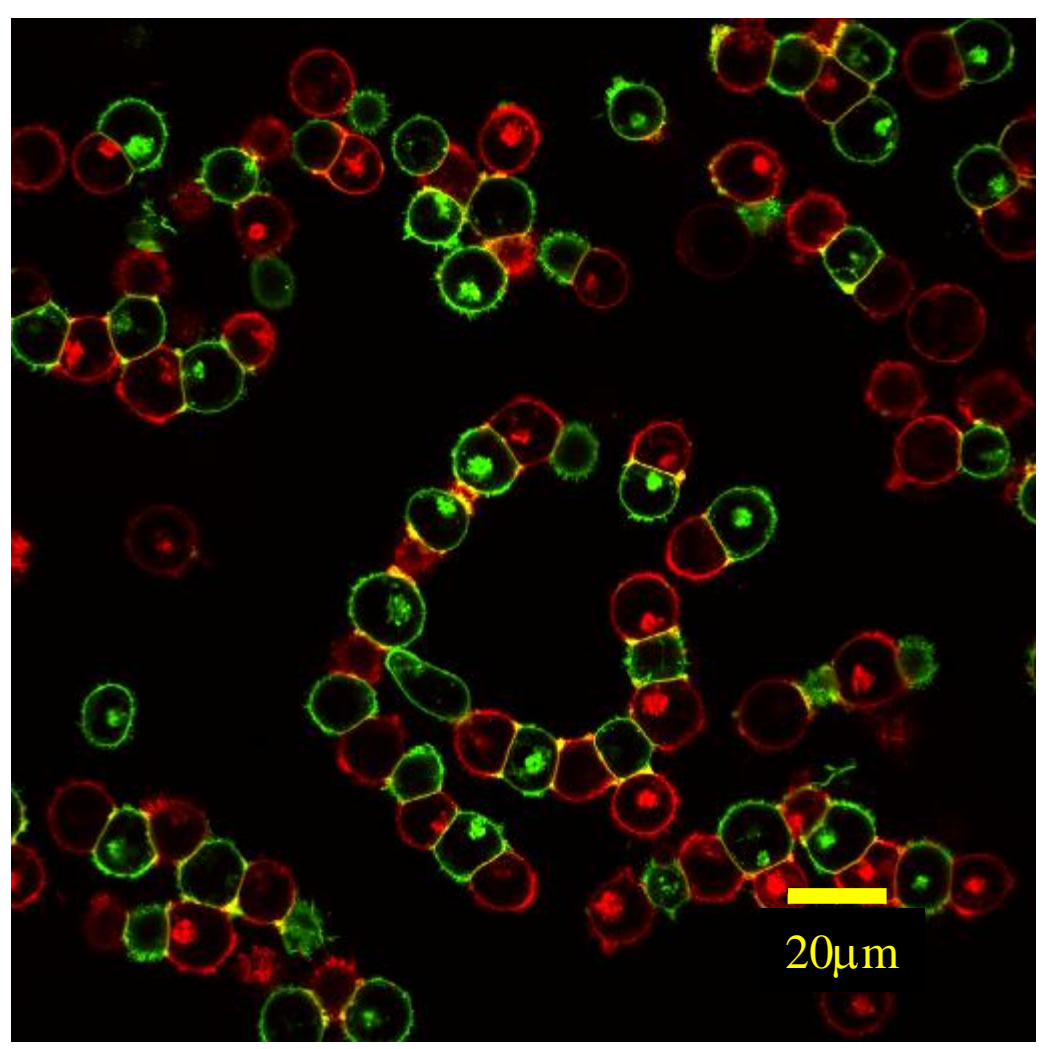

Figure 6 


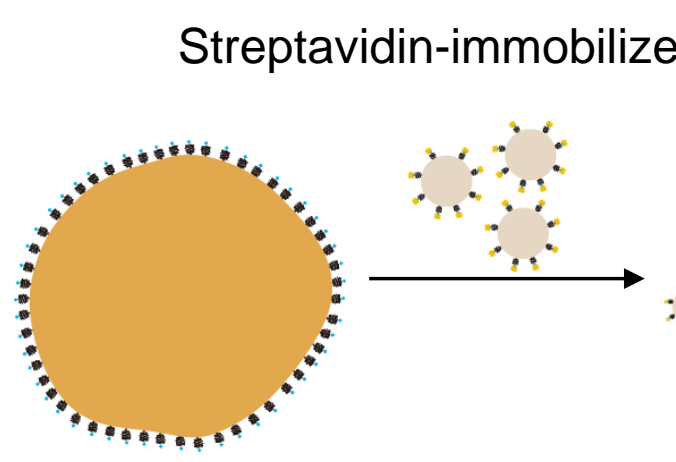

Biotin-PEG-lipid modified islets

(c)
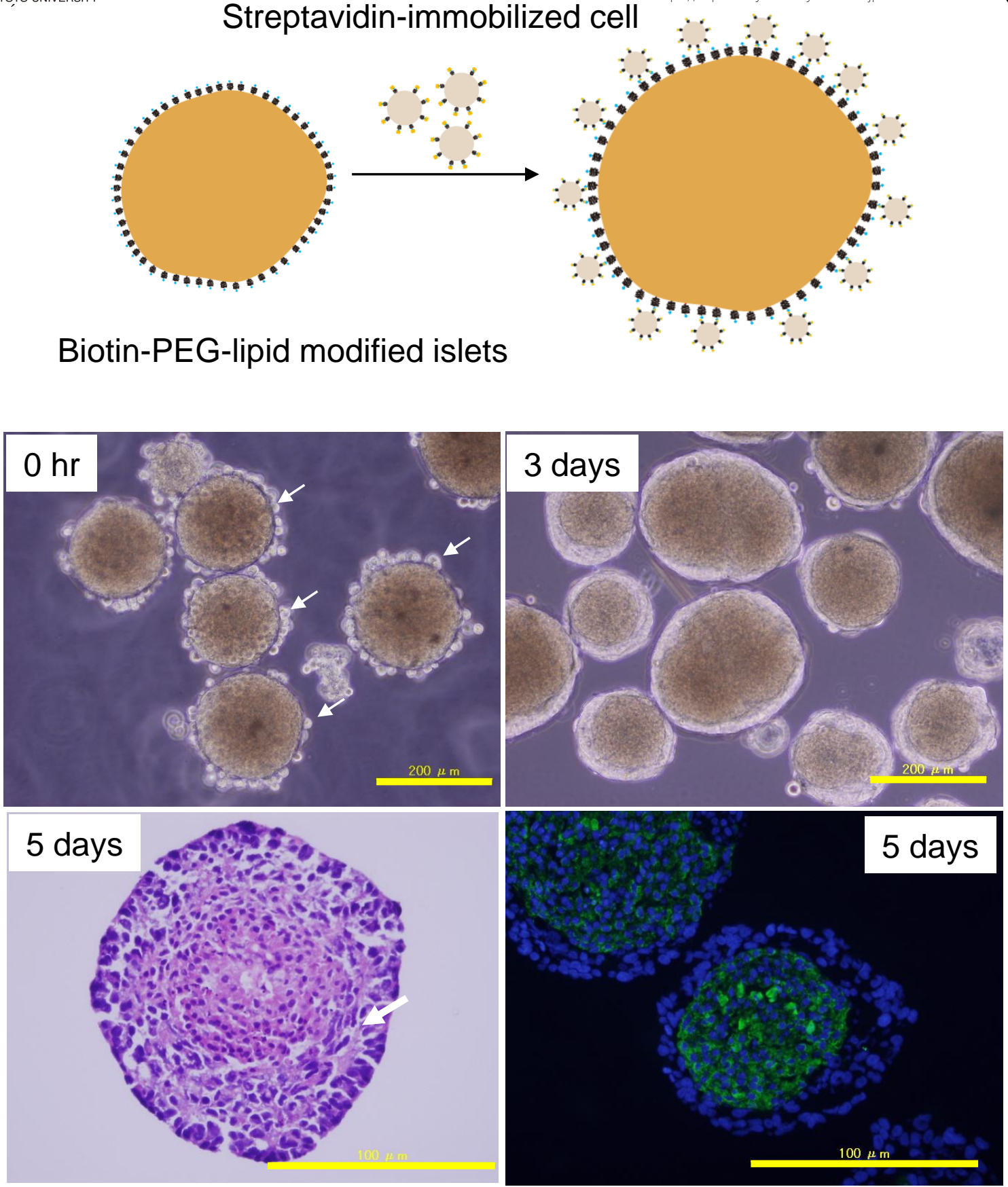

(b)

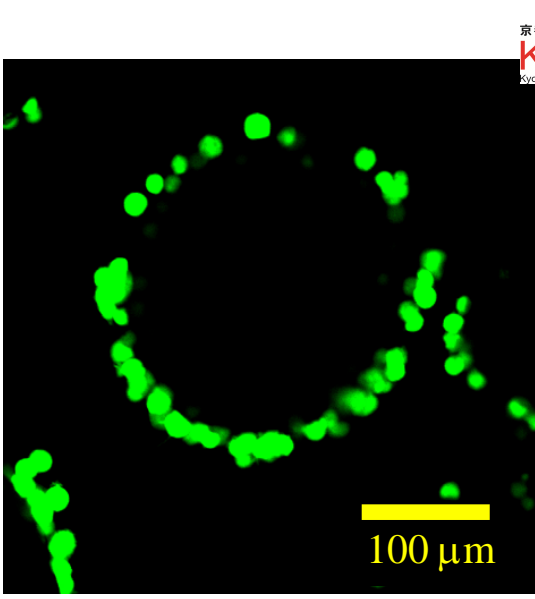

(d)
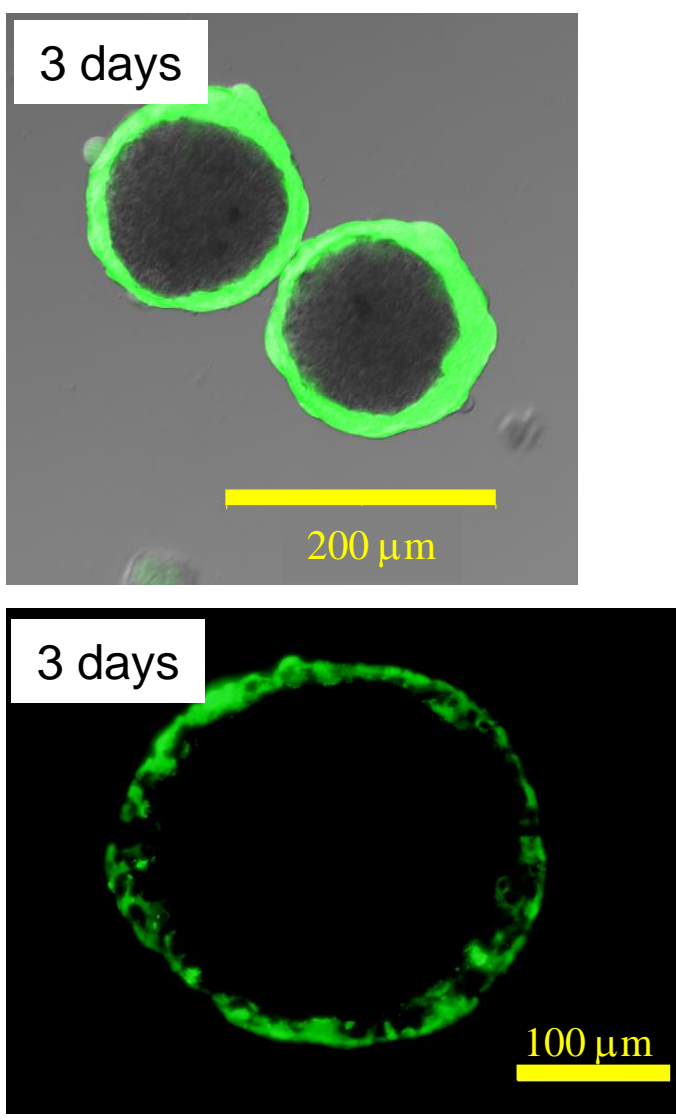

Figure 7 
EB
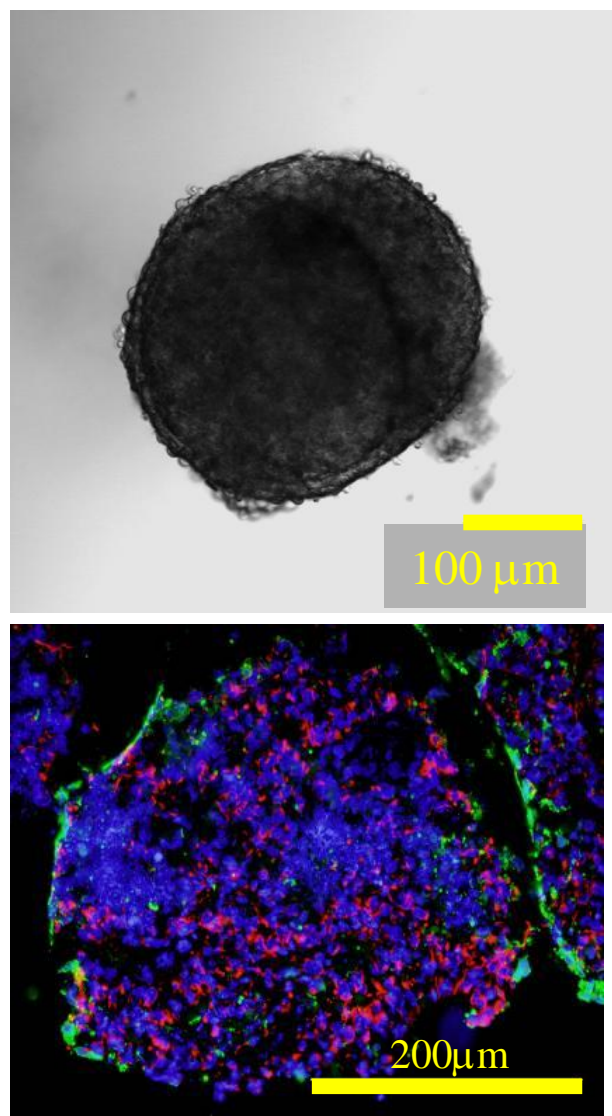

HEK293/EB
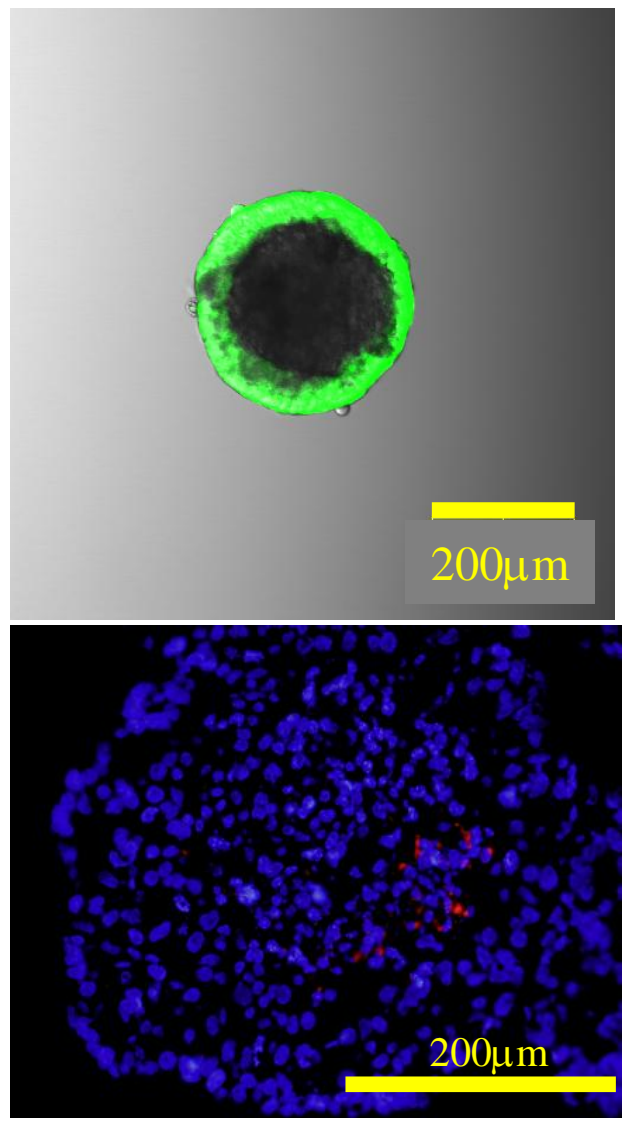

PA6/EB

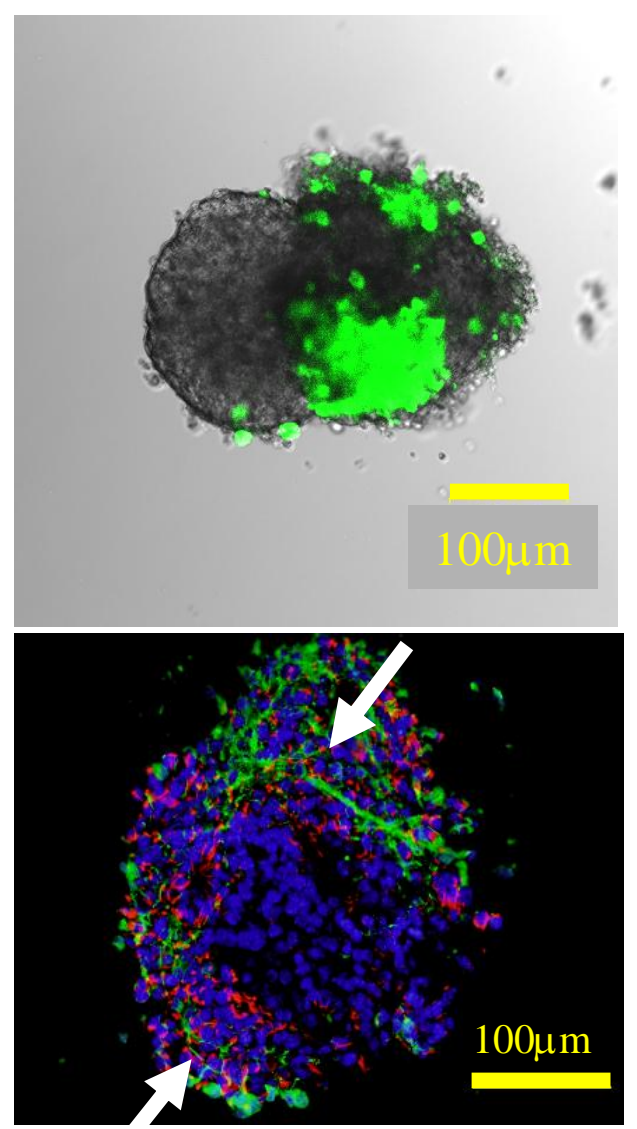

Figure 8 